\title{
VALORACÁO DA LEITURA POR PROFESSORES DO ENSINO MÉDIO: CONSIDERAÇÕES PARA A MOTIVAÇÃO PARA LEITURA DE ESTUDANTES
}

\section{Elsa Maria Mendes Pessoa Pullin Maria Gomes de Carvalho}

\begin{abstract}
RESUMO
Valorações de cunho afetivo e social dinamizam as relações cognitivas, que cada indivíduo mantém com as produções e artefatos de sua cultura. Respondem, ainda, pela importância e motivação para lerem. O presente trabalho objetivou identificar as funções que professores do Ensino Médio atribuem à leitura. Contamos com a participação de 14 professores de uma escola pública, que oportuniza a formação de professores para os anos iniciais da Educação Básica. Para a coleta de dados foi utilizada a Escala de Funções de Leitura, proposta por Greaney e Newman (1990). Constatou-se que as funções de leitura mais valorizadas foram as de: aprendizagem; lazer; utilidade; estímulo. A análise das correlações, pela valoração atribuída pelos participantes às funções da leitura, apontou oito significativas que se distribuíram de $0,64 \mathrm{a}^{+} 0,75$. As relações mais fortes foram registradas entre lazer e as funções de estímulo e fuga e entre aprendizagem e estímulo. O conjunto dos resultados obtidos reafirma a força das condições de vivência em um dado contexto sócio-histórico, usando-se como parâmetro os resultados da última pesquisa realizada pelo Instituto Pró-Livro. São assinalados alguns dos possíveis efeitos gerados para a motivação dos alunos para lerem, bem como assinaladas algumas limitações do presente trabalho e sugeridas possibilidades que as contornem para futuros trabalhos.
\end{abstract}

\section{PALAVRAS-CHAVE}

Leitura; Funções da leitura; Motivação para a leitura

\section{THE IMPORTANCE OF READING FOR HIGH SCHOOL TEACHERS: CONSIDERATIONS FOR STUDENTS' MOTIVATION TO READ}

\begin{abstract}
Affective and social value attributions stimulate the cognitive relations that each individual maintains with production and artifacts of his culture. They are also responsible for both the importance and motivation of reading. The present study aimed at identifying the roles High School teachers attribute to reading. The investigation relied on the participation of 14 teachers from a state school, which offers teachers' education for the initial years of Primary School. For the data collection, the Functions of Reading Scale, proposed by Greaney e Newman (1990), was utilized. It was verified the most valued reading functions were: learning, leisure, utility, and stimulus. The correlations analysis, by means of the value attributed, by the participants, to reading functions pointed to eight significant values, distributed from 0.64 to $^{+} 0.75$. The strongest relations were registered between leisure and the functions of stimulus and escape and between learning and stimulus. The set of results obtained reaffirms the strength of living conditions in a given social-historical context, by using, as a parameter, the results of the latest research carried out by Instituto Pró-Livro. Possible effects generated for students' motivation to read are appointed, and some limitations of the present study are remarked. In addition, some suggestions are made with the purpose of overcoming these limitations in future studies.
\end{abstract}

KEYWORDS

Reading; Reading functions; Motivation to read 


\section{PESQUISA \\ Área Temática: Ensino de Psicologia \& Psicologia Educacional Número Especial: Motivação}

\section{INTRODUÇÃO}

As sociedades contemporâneas requerem para atendimento às suas diversas demandas de leitores que sejam competentes, autônomos e críticos em face das produções, práticas e artefatos culturais e não apenas capazes de decodificá-los e codificá-los. A exigência atual decorre de um cenário sócio-político que exige a participação de todos para a construção de uma sociedade em que prevaleça a justiça e igualdade entre seus membros (GIMENO SACRISTÁN, 2008).

Os usos comuns da linguagem, nomeadamente aqueles que empregam os recursos lingüísticos, viabilizam que a língua se torne um recurso imprescindível para a memória individual e social (JEAN, 2002). Neste caso, as produções escritas, independente do suporte utilizado, propiciam "o repositório objetivo de vastas acumulações de significados e experiências" (BERGER; LUCKMANN, 2001, p. 57), de uma dada comunidade, bem como abrem a possibilidade de que essa herança cultural possa ser transmitida às gerações mais jovens.

A apropriação da herança simbólica e cultural, por parte das novas gerações, deve-se, por conseguinte e, em grande parte, às possibilidades franqueadas pelo uso da linguagem, porque esta permite não só “construir símbolos altamente abstraídos da experiência diária, mas também 'fazer retornar' esses símbolos apresentando-os como elementos objetivamente reais na vida cotidiana" (BERGER; LUCKMANN, 2001, p.61. Grifos dos autores).

Em face das funções atribuídas à escola nas sociedades modernas, compete aos professores, em todos os níveis de ensino das diversas áreas do saber e não apenas ao professor de Língua Portuguesa (GUEDES; SOUZA, 2007), a responsabilidade de ensinarem as muitas formas de leitura e escrita legitimadas e exigidas para o exercício da cidadania (FREIRE, 1986; SILVA 1998).

Sabe-se, ainda, que quaisquer atividades, como as prescritas em situações escolares, adquirem significado para os que as devem cumprir se elas forem percebidas como meios para que consigam atingir objetivos por eles desejados. Isto é, alunos podem, ou não, sentir-se motivados a cumprir tarefas e para aprender um determinado conteúdo, devido ao 
valor instrumental que associem à realização da atividade proposta (ECCLES; WIGFIELD, 2002). Na perspectiva teórica destes últimos autores, a valorização subjetiva de uma determinada atividade pode ser compreendida mediante quatro elementos: a importância atribuída ao sucesso na realização daquela tarefa ou na afirmação do autoconceito; o interesse inerente à própria atividade; a percepção de utilidade da sua realização, para, por exemplo, auxiliar no alcance de metas pessoais; e o equilíbrio entre as exigências da tarefa (custo) e os resultados obtidos (benefício).

Segundo Brophy (1999), o conhecimento derivado de diversas teorias motivacionais contemporâneas permite afirmar que uma determinada atividade ou conhecimento terá o potencial de motivar os alunos na medida em que elas sejam percebidas como algo de grande valor e que se constituam em tarefas autênticas. Isso, porque os alunos não devem simplesmente compreender o que estejam aprendendo, mas valorizar as atividades ou conhecimentos que lhes são ensinados. Como este autor prefere dizer, quando apreciem a atividade que deve ser cumprida, isto é, a valorizem, esse sentimento é uma ótima razão para que a realizem e aprendam.

Pode-se supor que, em salas de aula, essa valorização não ocorra de modo espontâneo em relação ao que precisa ser aprendido, pois os estudantes trazem para esse contexto vivências diversas e um leque de outras opções de atividades que lhes são geradoras de interesse e satisfação. A noção de aprendizagem com compreensão, apreciação e que comporte as aplicações para a vida de um determinado conteúdo foi defendida por Brophy (1999). Esta noção implica em muito mais do que o interesse ${ }^{1}$ dos alunos por um determinado tópico: inclui estratégias cognitivas e metacognitivas de controle que correm junto com componentes afetivos. Apesar de esse tipo de motivação para aprender não possa ser ensinado diretamente em seu todo, alguns dos seus componentes cognitivos e habilidades podem e devem ser trabalhados pelo professor, quando exerce seu papel de mediador. Assim o faz, quando comunica e por seus comportamentos modela "as atitudes, valores, expectativas e disposições relacionadas à ação" (BROPHY, 1999, p. 81), influenciando, desse modo, seus alunos. O professor, então, pode e deve levar o aluno a perceber o valor, a importância daquela atividade ou conhecimento.

\footnotetext{
${ }^{1}$ Uma análise crítica e histórica do papel do interesse para a motivação é apresentada por Hidi, et al. (2004) 
A importância que o aluno atribui à atividade, por conseguinte depende em grande parte do valor que o próprio professor atribui à mesma. Como afirma Brophy (1999, p. 82) “[...] as pessoas, especialmente, as crianças adquirem a maioria das atitudes de autoreferência, crenças, expectativas e disposições para agir, quando expostas a influências socializadoras". Estas se fazem presentes quando do ensino de conhecimentos e habilidades, e quando da verbalização dos valores, crenças e expectativas relacionadas à atividade a ser cumprida por parte dos agentes socializadores, pais, professores, orientadores.

Argumentou-se que as dimensões valorativas dos professores acerca das atividades propostas a seus alunos são fundamentais. No campo da leitura, em face da falta de hábito da maioria da população (AMORIM, 2007), há que os professores fiquem ainda mais atentos quanto aos modos como se relacionam com ela, dados os efeitos potencializadores desses socializadores para o grau e tipo de relações que os alunos possam manter com os materiais escritos, tema deste trabalho.

Os objetivos a serem alcançados e o valor instrumental de quaisquer tarefas são definidos nas relações que o indivíduo mantém com o seu meio, especialmente pelos efeitos das valorações legitimadas pelas práticas educativas. Na escola, por exemplo, os feedbacks que o professor propicia afetam não só o processo de aprendizagem, como a motivação dos alunos (PINTRICH; SCHUNK,1996; ANDERMAN et al., 2001; BZUNECK, 2001, HIDEI et al. 2004; HUSMAN et al. 2004, entre outros).

A importância que o professor atribui, ou não, a um conteúdo e a uma atividade de sua disciplina, revela-se em suas verbalizações e em seus comportamentos. Mais do que isso, influencia o respectivo significado valorativo que passa a ser atribuído pelos alunos a esse conteúdo ou atividade (BROPHY, 1999; LINNENBRICK; PINTRICH, 2004). Esse efeito, qual contágio afetivo (BZUNECK, 2010), pode delimitar a emergência da motivação intrínseca para que o aluno aprenda e realize as tarefas que lhe sejam prescritas ou as que ele decida fazer. Isso, porque a persistência e os níveis de desempenho dos alunos em atividades escolares têm sido explicados, entre outros fatores, pelos valores que eles atribuem à atividade (BROPHY, 1999; WIGFIELD; ECLLES, 2000; LINNENBRICK; PINTRICH, 2004 ). 
$\mathrm{O}$ valor que os indivíduos atribuem à leitura decorre dos modos idiossincráticos de estar no e ler o mundo, adquiridos nos distintos processos de socialização da herança cultural, desde a familiar à do seu grupo. Dentre esses processos destacam-se os propiciados pelos efeitos das experiências de letramento e dos processos de ensino das diversas alfabetizações, ao longo de sua escolarização.

Por entender-se que algumas propostas de ensino da leitura não logram êxito, porque em seu bojo deixam de levar em conta os efeitos das dimensões afetivas e valorativas que os professores atribuem ao valor instrumental da leitura, propôs-se este trabalho. Por ele, pretende-se desvelar algumas dessas dimensões em um grupo específico de professores e propiciar condições para que o leitor deste trabalho, pela análise dos resultados obtidos, seja instigado a refletir, identificar e a (re)significar, caso necessário, a importância que atribui à leitura, suas práticas socializadoras e os possíveis efeitos para a motivação de outros para lerem. Especialmente, se for professor.

Conceitualmente, a leitura precisa ser percebida como uma prática social, que sofre os efeitos dos modos legitimados de ler (CAVALLO; CHARTIER, 1998), e como uma atividade individual (SCRIBNER; COLE 1999) de uma prática social e situada (MARCUSCHI, 1998). A história é fecunda em demonstrar que mudanças culturais, sociais e políticas geram consequências para as práticas de leitura, especialmente para as que decorrem das mudanças nos campos semânticos das palavras a ela relacionadas (GARCIA, 2004). Cabe ressaltar que a leitura e a escrita expressam modos inscritos e legitimados socialmente, alguns deles prescritos em documentos oficiais, pretensamente reguladores, por vezes, das práticas educativas que ocorrem nas instituições escolares.

Com efeito, qualquer que seja o sentido individual atribuído à leitura, o fato é que o sentido geral do campo semântico dessa palavra e das que lhe são relacionadas sempre envolvem um conjunto de saberes, cognitivos, afetivos e valorativos, engendrados na constituição subjetiva do indivíduo como leitor. Esse conjunto mantém vínculos fortes com as condições que lhe foram propiciadas pelas interações e nas quais participou como sujeito de uma dada comunidade sociocultural. Tais interações ocorrem, além do mais, na sua relação cotidiana com os artefatos culturais a que tem acesso. Nesse sentido, para se investigar a compreensão simbólica dos sujeitos acerca da leitura importa não só o que eles lêem, mas as 
razões e os modos como a realizam (BOURDIEU; CHARTIER, 1996), porque os textos podem tanto "fazer-se ler [como] dar-se a ler" (GOULEMOUT, 1996, p. 116).

Larrosa (2002), ao acercar-se da leitura, toma-a como exemplo de uma atividade de formação, ressaltando a relevância de esta ser sempre percebida como uma atividade relacionada à subjetividade do leitor. Para tanto, adverte que a leitura é uma atividade que "nos constitui ou nos põe em questão naquilo que somos" (LARROSA, 2002, p.133). Além disso, pela leitura de textos "nós podemos, [...] ser transformados por tais experiências, de um dia para o outro ou no transcurso do tempo" (LARROSA, 2002, p. 138).

A leitura, em síntese, é uma prática sociocultural que possibilita a quem a realiza acesso a informações e à (re)construção dos seus saberes. O ato de ler é ocasionado por muitas razões, algumas delas configuradas pelas condições de que o indivíduo dispõe para se posicionar e se relacionar com as pessoas e os artefatos culturais que constituam sua realidade. Para compreender o indivíduo e suas produções, no caso as relacionadas ao ler, há que se considerar suas experiências que respondem pela apropriação e constituição de algumas redes de significados, que lhe permitem atribuir sentido a suas vivências, além de o fazer sentir-se membro de sua comunidade. A identificação dessas redes proporciona a outros compreenderem o comportamento do indivíduo ou de um grupo. No caso da leitura, a atribuição de significados e dos manifestados às suas funções viabiliza relacionar os aspectos e dimensões preponderantes e influenciadoras da probabilidade de sua ocorrência: os de cunho pessoal, para atendimento a necessidades de realização, selecionadas e priorizadas pelo indivíduo para si, ou dos que atendem simplesmente às exigências postas por outros, como é o caso de leituras prescritas na escola e nem sempre valorizadas por quem tem que as realizar.

Nessa perspectiva, Chartier (1991) demonstra, no campo da história social, a importância de que sejam identificadas as representações que permeiam os fazeres de cada um, seja em relação consigo, seja com o outro e com os objetos que circulam em seu mundo. Ao analisar a construção do sentido pelo leitor, esse autor expõe que seus fazeres não ocorrem separados da materialidade que se estabelece entre "mundo do texto" e "mundo do leitor" (CHARTIER, 1991, p.178). Nem o texto, nem os modos de ler são entidades abstratas e universais, visto que a organização do objeto que contém o texto dirige o leitor em sua leitura, bem como em sua “apreensão e compreensão" (CHARTIER, 1991, p. 178). Essas atividades 


\section{PESQUISA \\ Área Temática: Ensino de Psicologia \& Psicologia Educacional Número Especial: Motivação}

ocorrem em um jogo inscrito num espaço, por conseguinte situado, que dirige no leitor a "relação consigo ou com o outro" (CHARTIER 1991, p.181).

Entre os argumentos desse autor em defesa da sua proposição para análise da leitura, sob uma perspectiva cultural, destaca-se a da sua recomendação quanto a que qualquer análise deve centrar a "atenção sobre as estratégias simbólicas que determinam posições e relações e que constroem, para cada classe, grupo ou meio, um ser-percebido constitutivo de sua identidade." (CHARTIER 1991, p.184).

Como demonstrado, até aqui, a leitura, quando entendida como uma atividade individual de uma prática social, implica em que sejam ressaltados os efeitos da dimensão simbólica a ela relacionada, individualmente construída nas relações sociais. A partir dos significados que os sujeitos, ou grupo, atribuem a cada uma dessas relações, no caso que interessa para o presente trabalho, as relativas ao processo de formação de novos leitores destacam-se, pela importância impressa nos fazeres que ocorrem em instituições que visam essa formação, nomeadamente em escolas. Atualmente e de modo particular, nas instituições escolares, os efeitos das marcas da dimensão simbólica responsáveis por modos distintos de compreender e praticar a leitura eclodem como problemas postos, frequentemente, como desafios que devem ser solucionados pelos professores, nem sempre cientes da força dessas marcas (SQUIRES; BLISS, 2004).

Por essa perspectiva, e no que importa para o presente relato, os dizeres e fazeres dos professores, por exemplo, acerca de leitura, decorrem das suas concepções e crenças (RAYNER et al., 2001; LINEK et al., 2006). A importância atribuída às funções da leitura pode ser avaliada pela escala proposta por Greaney e Newman (1990), traduzida e adaptada para o Brasil, no mesmo ano, por Geraldina Porto Witter. Esses autores definiram, após uma análise cuidadosa dos dados obtidos junto a grupos de distintas culturas, as funções principais que eles em suas respostas escritas registraram para a questão 'O que é ler?'. Categorizadas as respostas e submetidas a juízes independentes as categorias definidas que deram conta dos dados foram transformadas em afirmações, cinco por função, componentes da escala usada, desde então, junto a distintas populações para avaliar a importância funcional atribuída à leitura. As dez funções fundamentais constatadas para a leitura e avaliadas pela escala 
proposta são: (1) aprendizagem; (2) lazer; (3) fuga; (4) estímulo; (5) preencher tempo; (6) alvos sociais definidos; (7) moralidade; (8) autorrespeito; (9) flexibilidade e (10) utilidade.

Mediante o exposto, o presente trabalho buscou identificar qual a importância da leitura, pelas funções a ela atribuídas por professores do Ensino Médio, com o intuito de considerar possíveis decorrências para a motivação da leitura em seus alunos.

\section{MÉTODO}

\section{Participantes}

A amostra de participantes deste trabalho foi constituída por 14 professores de distintas áreas do conhecimento que trabalham em uma escola pública de Ensino Médio no período noturno, responsáveis por disciplinas junto ao curso de Formação de Docentes da Educação Infantil e dos anos iniciais do Ensino Fundamental - Normal. A predominância de mulheres foi evidente: $78,6 \%$ do grupo de participantes. No que concerne à idade, a maioria apresentava idade superior a 40 anos: entre 40 e 60 anos situavam-se $71,4 \%$, e os demais entre 28 e 39 anos. Todos os participantes $(\mathrm{N}=14)$ possuíam a formação acadêmica profissional mínima exigida para o exercício profissional no Ensino Médio, isto é, a graduação específica certificadora para o ensino na(s) disciplina(s) que conduziam. Desses, oito haviam completado curso(s) de pós-graduação lato sensu e um o mestrado. Em relação ao tempo de exercício profissional, 50\% estavam em atividade há mais de 30 anos.

\section{Instrumento e Procedimentos de Coleta de Dados}

Para a coleta de dados foi utilizada a Escala de Função de Leitura proposta por Greaney e Newman (1990). Esta escala tem sido usada com sucesso por diversos pesquisadores (LOPES; RIBEIRO 1992; OLIVEIRA, 1993; 1996; PULLIN, et al., 2001; CARVALHO, 2009; entre outros). A escala é constituída por 50 itens formulados sob a modalidade de afirmações simples, cada uma das quais é seguida por quatro opções de resposta (muito, mais ou menos, pouco, e nada) para que o respondente indique o grau de concordância ao enunciado no item. Entende-se que o grau de aceite aos enunciados informa a importância da leitura, em termos instrumentais, e o que indiretamente move o respondente ao ler. 
Logo após terem sido explicitados os objetivos e metas da pesquisa e obtida a assinatura do Termo de Consentimento Livre e Esclarecido, foi iniciada a coleta de dados. Esta foi individual e ocorreu na sala de professores da própria instituição, nos horários destinados a cada participante à "Hora Atividade".

\section{Procedimentos para a Análise dos Dados}

As respostas assinaladas na escala foram pontudas por protocolo, como segue: muito=3; mais ou menos=2; pouco $=1$; nada $=0$. Como cinco itens medem cada uma das 10 funções propostas pelo instrumento, o valor máximo de pontos individuais por função é 15 e, no instrumento, de 150 pontos. Esses totais, assim calculados, indicam a importância, isto é, a valoração do respondente para cada uma das funções da leitura e para a leitura, de modo geral.

Com vistas a uma análise interpretativa desses valores foram utilizados os critérios propostos por Oliveira (1993). Essa autora propôs três níveis para medir a força relativa da importância das funções avaliadas pela escala de Greaney e Newman (1990), tendo por base a pontuação obtida nos protocolos individuais. Estipulou como nível alto, valores entre 11 e 15 pontos, nível médio para pontuações entre 6 e 10 pontos, e nível baixo para valores compreendidos entre 0 e 5 pontos.

Para avaliar a força das relações entre as funções foi usado o Teste $U$ de Sperman (SIEGEL, 1977), tendo-se definido como nível de significância (n.s.) o de uma p< 0,50.

\section{RESULTADOS E DISCUSSÃO}

Nenhum dos participantes alcançou a pontuação máxima em todas as funções. Registrou-se que a pontuação obtida pelo grupo de participantes $(\mathrm{N}=14)$ situou-se no intervalo entre 74 e 112 pontos. A Tabela 1 apresenta as pontuações individuais por participante. Como se pode verificar, os participantes (P2 e P11) foram os que obtiveram as pontuações dos extremos daquele intervalo. 
TABELA 1

Pontuação dos participantes na valoração das funções de leitura

\begin{tabular}{|c|c|c|c|c|c|c|c|c|c|c|c|}
\hline & \multicolumn{10}{|c|}{ FUNÇÕES } & \multirow[b]{2}{*}{$\begin{array}{c}\text { Total } \\
\text { Individua }\end{array}$} \\
\hline & 1 & 2 & 3 & 4 & 5 & 6 & 7 & 8 & 9 & 10 & \\
\hline $\mathrm{P} 1$ & 13 & 10 & 5 & 7 & 7 & 12 & 6 & 4 & 11 & 13 & 88 \\
\hline $\mathrm{P} 2$ & 15 & 15 & 8 & 15 & 10 & 7 & 15 & 6 & 6 & 15 & 112 \\
\hline P3 & 15 & 15 & 10 & 12 & 5 & 3 & 14 & 6 & 9 & 13 & 102 \\
\hline P4 & 11 & 12 & 3 & 9 & 5 & 6 & 11 & 3 & 13 & 13 & 86 \\
\hline P5 & 14 & 15 & 13 & 14 & 11 & 4 & 8 & 0 & 13 & 8 & 100 \\
\hline P6 & 11 & 11 & 6 & 10 & 10 & 12 & 10 & 7 & 7 & 14 & 98 \\
\hline $\mathrm{P} 7$ & 13 & 13 & 7 & 11 & 6 & 4 & 9 & 1 & 10 & 9 & 83 \\
\hline P8 & 14 & 15 & 6 & 14 & 5 & 8 & 10 & 11 & 4 & 13 & 100 \\
\hline P9 & 14 & 14 & 8 & 11 & 7 & 12 & 14 & 4 & 8 & 15 & 107 \\
\hline P10 & 13 & 14 & 7 & 14 & 7 & 7 & 3 & 0 & 4 & 10 & 79 \\
\hline P11 & 11 & 8 & 5 & 7 & 2 & 9 & 10 & 6 & 6 & 10 & 74 \\
\hline P12 & 13 & 15 & 12 & 12 & 9 & 5 & 7 & 0 & 7 & 11 & 91 \\
\hline $\mathrm{P} 13$ & 13 & 11 & 7 & 12 & 2 & 9 & 11 & 4 & 9 & 14 & 92 \\
\hline P14 & 15 & 12 & 5 & 13 & 5 & 8 & 11 & 5 & 13 & 13 & 100 \\
\hline $\begin{array}{l}\text { Total } \\
\text { Geral }\end{array}$ & 185 & 180 & 102 & 161 & 91 & 106 & 139 & 57 & 120 & 171 & 1312 \\
\hline
\end{tabular}

Codificação: 1=Aprendizagem; 2=Lazer; 3=Fuga; 4=Estimulo; 5=Preencher oTempo; 6=Alvos Sociais Definidos; $\mathbf{7}=$ Moralidade; $8=$ =Autorrespeito; $\mathbf{9 = F l e x i b i l i d a d e ; ~} \mathbf{1 0}=$ Utilidade

Os resultados apresentados na tabela acima demonstram que as funções de aprendizagem, de lazer, de utilidade, de estímulo e de moralidade foram as que atingiram a pontuação máxima, entre os participantes. Destacam-se as pontuações de P2, por ter atribuído tal importância a todas essas funções. Os demais participantes, ora obtiveram essa pontuação para as funções aprendizagem e lazer (P3), ou apenas à de lazer (P5; P8; P12), à de aprendizagem (P14) e à de utilidade (P9). As funções menos valorizadas pelos participantes foram as de fuga, preencher tempo, e autorrespeito (Tabela 1).

Em parte, os resultados do presente trabalho convergem com os obtidos em outros estudos brasileiros, inclusive com os realizados junto a populações distintas. Por exemplo, Lopes e Ribeiro (1992) constatarem, junto a estudantes do curso de Biblioteconomia, que as funções mais valorizadas foram as de: aprendizagem, lazer e utilidade. Oliveira (1993), tendo conduziu seu estudo, junto a alunos de graduação e pós-graduação, registrou que as funções 
de leitura mais valorizadas foram as de aprendizagem, utilidade e lazer. Martins e Cosenza (2004), no levantamento que realizaram junto a professores universitários, registraram que as funções de leitura mais valorizadas incluíam: aprendizagem, lazer e alvos sociais definidos. Moreira (2007), em estudo realizado junto a professores e alunos de um curso do Ensino Médio para a formação de professores, verificou que as funções mais valorizadas foram as de aprendizagem, utilidade e lazer.

O conjunto de pesquisas e este trabalho demonstram valorações similares para as funções atribuídas à leitura, por estudantes do Ensino Médio e de Ensino Superior, da graduação e da pós e por professores do Ensino Superior e de Ensino Médio. As funções instrumentais reportadas à leitura para aprendizagem e lazer são comuns, independente do grupo de participantes. A função de utilidade é a mais ressaltada por alunos, independente do grau de escolarização, enquanto que a de alvos sociais definidos foi apenas mais valorizada por professores universitários.

Quando transposta a proposição de Oliveira (1993) para análise dos dados gerais obtidos junto aos participantes deste trabalho, observa-se que, dado o número de participantes $(\mathrm{N}=14)$, a pontuação necessária para afirmar que o grupo atribui um nível alto à função, a soma dos pontos individuais deveria situar-se entre 154 e 210 pontos. Somatórias distribuídas no intervalo de 84 a 140 pontos informariam, então, uma valoração média para a função por parte do grupo, enquanto que totais abaixo de 70 indicariam, por sua vez, uma valoração baixa da função.

A linha inferior da Tabela 1 demonstra que as funções de aprendizagem, de lazer, de utilidade e de estímulo foram as que atingiram um nível alto de valoração, pelos totais registrados $(185 ; 180 ; 171 ; 161)$. As funções de moralidade (139) e de flexibilidade (120); de alvos sociais definidos (106 pontos); de preencher o tempo (91 pontos) demonstram um nível médio de valoração, por parte do grupo de participantes. A única função para a qual pode-se afirmar que os participantes atribuem uma menor importância é a de autorrespeito, pela pontuação obtida (57 pontos), conforme critérios adotados. 
Quando utilizada a proposta de Oliveira (1993) para analisar a valoração geral das funções por participante, tendo-se por foco as dez funções, uma valoração alta das mesmas deveria situar-se no intervalo de 110 a 150 pontos e uma média deveria abranger pontuações situadas entre 60 e 109 pontos; por sua vez, funções que estivessem abaixo de 59 pontos indicariam uma valoração baixa.

A leitura da última coluna direita da Tabela 1 permite que se identifiquem as pontuações obtidas nas dez funções por participante. Como se pode constatar, a maioria dos participantes atribuiu uma valoração média para as funções, visto os resultados terem se distribuído pelo intervalo de 74 a 100 pontos. Apenas P2 obteve valores superiores (112 pontos), o que permite afirmar que para este participante as dez funções passíveis de serem medidas pelo instrumento utilizado têm uma importância alta. Entretanto, as funções de estímulo, de moralidade e a de preencher o tempo têm para ele uma valoração média e as de fuga e de autorrespeito foram valorizadas no nível baixo, conforme critérios de Oliveira (1993).

De acordo com Greaney e Newman (1990), o leitor maduro considera a relevância funcional da leitura em cada uma das dez funções. Entretanto como demonstrado, o grupo de participantes atribui individualmente importância média à leitura para a consecução dessas funções. O fato de se ter registrado que o grupo atribui às funções de aprendizagem, de lazer, de utilidade e de estímulo um nível alto de valoração pode ser explicado pelas condições socioculturais, as quais, pelos efeitos de suas práticas sociais, tendem a reforçar essas valorações, conforme constatado nas pesquisas arroladas anteriormente.

No caso deste estudo, pelas características dos participantes, professores do Ensino Médio atuando na habilitação do Magistério, as práticas induzidas e prescritas nos discursos oficiais dos documentos das atuais políticas educacionais podem dar sustentação a essa hipótese. Contudo, de modo geral, pode-se afirmar que os resultados obtidos apontam para uma perspectiva reducionista acerca de leitura, movida apenas para dar conta de demandas próximas, na maioria das vezes circunscritas ao exercício do ofício profissional. 
Estudos anteriores indicam que as funções atribuídas à leitura, medidas pelo instrumento utilizado se correlacionam. (LOPES; RIBEIRO 1992; PULLIN et al., 2001). Entre as 42 possibilidades de correlação, apenas oito foram significativas e com índices de variação entre ${ }^{-0,64 *} \mathrm{e}^{+} 0,75^{*}$.

As correlações significativas encontradas foram entre as seguintes funções: aprendizagem e lazer $\left(0,65^{*}\right)$; aprendizagem e estímulo $\left(0,70^{*}\right)$; lazer e fuga $\left(0,74^{*}\right)$; lazer e estímulo $\left(0,75^{*}\right)$; lazer e alvos sociais definidos $\left(0,64^{*}\right)$; fuga e estímulo $\left(0,53^{*}\right)$; alvos sociais definidos e utilidade $\left(0,55^{*}\right)$; moralidade e utilidade $(0,70 *)$; autorrespeito e utilidade $(0,54 *)$.

Os registros dos resultados obtidos pelo Teste $U$ de Sperman podem ser lidos na Tabela 2.

TABELA 2

Correlações entre as funções de leitura $(p<0,05)$

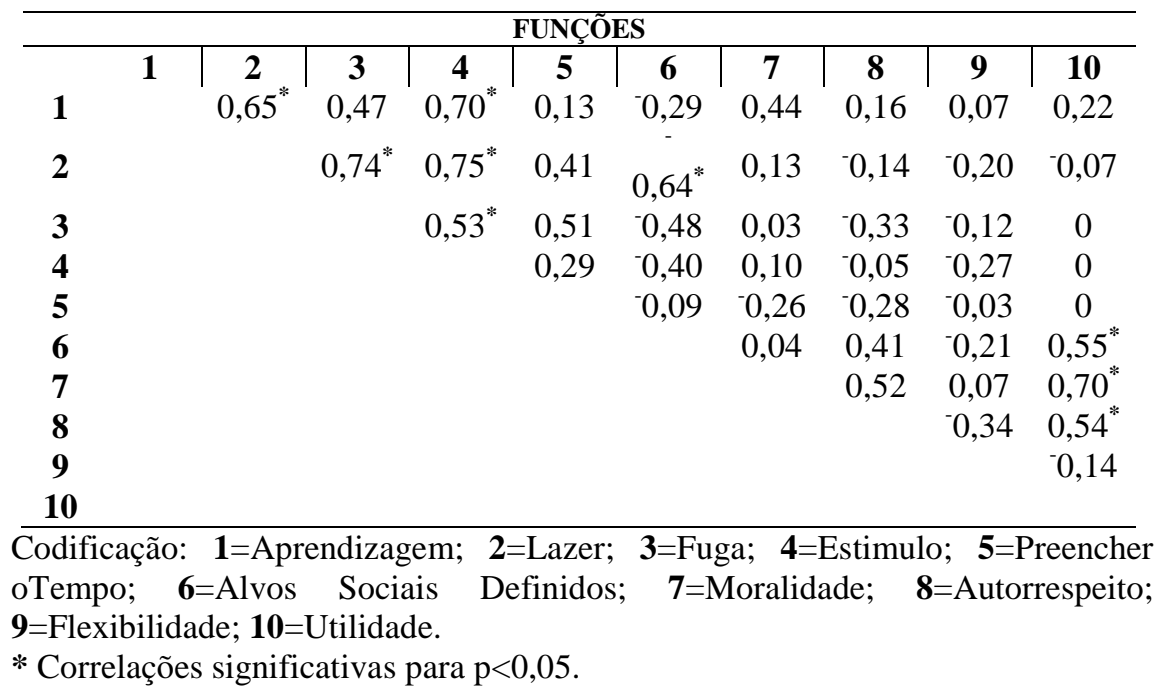

Quando comparados esses resultados com os de outras pesquisas verifica-se, inicialmente, que os intervalos de correlação são distintos. Lopes e Ribeiro (1992) informaram que as correlações que encontraram variavam de ${ }^{-0,81^{*}}$ a $0,86^{*}$ e Pullin et al. (2001) encontraram correlações que variaram de $0,45^{*}$ a $0,81^{*}$, isto é, os resultados dessas pesquisas apresentaram uma força de relação positiva entre as funções, superior à obtida no presente trabalho $(0,75)$. Entretanto, o estudo de Pullin et al. (2001) não registra relações negativas significativas entre as funções, como constatado por Lopes e Ribeiro (1992), entre 
fuga e estímulo $(-0,81)$ e entre fuga e alvos sociais definidos $(-0,63)$, e entre lazer e alvos sociais definidos $\left(-0,64^{*}\right)$, como verificado neste trabalho.

Os resultados deste trabalho diferem, ainda, dos obtidos por Lopes e Ribeiro (1992) quanto à não-relação constatada entre as funções. No estudo dessas autoras, a análise dos resultados entre aprendizagem e lazer e entre preencher o tempo e alvos sociais demonstrou a ausência de relação entre as mesmas. A Tabela 2 apontou esse resultado entre a função utilidade e as de fuga, de estímulo e a de preencher o tempo.

Pela pertinência para este trabalho destacam-se as correlações constatadas por Lopes e Ribeiro (1992) e Pullin et al. (2001). No trabalho das primeiras autoras, foram demonstradas correlações significativas entre as funções de aprendizagem e alvos sociais definidos $\left(0,76^{*}\right)$, lazer e flexibilidade $\left(0,78^{*}\right)$, fuga e estímulo $\left(-0,81^{*}\right)$, fuga e alvos sociais definidos $\left(0,61^{*}\right)$, estímulo e alvos sociais definidos $\left(0,86^{*}\right)$; alvos sociais definidos e autorrespeito $\left(0,68^{*}\right)$; alvos sociais definidos e utilidade $\left(0,74^{*}\right)$, moralidade e autorrespeito $\left(0,69^{*}\right)$, autorrespeito e utilidade $\left(0,64^{*}\right)$.

Os resultados obtidos por Pullin et al. (2001) informam as seguintes correlações positivas e significativas entre as valorações atribuídas às seguintes funções da leitura: aprendizagem e estímulo $\left(0,62^{*}\right)$, lazer e fuga $\left(0,57^{*}\right)$, fuga e preencher o tempo $\left(0,81^{*}\right)$.

Como se pode concluir, quanto à correlação entre a funções observam-se algumas similaridades entre as pesquisas apresentadas com alguns dos resultados deste trabalho, nomeadamente, entre as correlações significantes verificadas entre lazer e fuga, e entre aprendizagem e estímulo no presente trabalho, com as encontradas por Pullin et al. (2001).

Entretanto, os resultados diferem, de modo geral, dos obtidos por Lopes e Ribeiro (1992), por exemplo, na relação da função de moralidade com as funções de autorrespeito e de utilidade. No presente estudo foi confirmada, como significativa, a relação entre as funções de moralidade e utilidade $\left(0,70^{*}\right)$, e, no das outras autoras, essa função está relacionada à função de autorrespeito $\left(0,69^{*}\right)$. O resultado da força da relação entre as funções de fuga e de estímulo obtido neste trabalho foi na direção oposta e com tendência inversa $\left(0,53^{*}\right)$ à encontrada por Lopes e Ribeiro (1992), visto o valor observado por essas autoras ter sido de ( $0,81 *)$. 
Tanto no presente trabalho quanto no de Pullin et al. (2001) não foi encontrado um total de relações significantes entre a função de alvos sociais definidos com as demais, como o registrado por Lopes e Ribeiro (1992).

É importante ressaltar que as correlações significativas encontradas entre as funções de lazer e de fuga $\left(0,74^{*}\right)$, e entre a de lazer e a de estímulo $\left(0,75^{*}\right)$, por um lado são instigantes e preocupantes, especialmente quanto aos efeitos do trato da leitura por parte dos professores participantes junto a seus alunos, alguns deles futuros professores. Se para esses participantes, por um lado, a leitura é fonte de lazer e de fuga dos problemas do cotidiano, por outro, a função de lazer preenchida pela leitura correlaciona-se negativa e significantemente com a de alvos sociais definidos $(-0,64 *)$.

A leitura da Tabela 2, como a de quaisquer outros materiais simbólicos, viabiliza múltiplas interpretações. Entretanto, umas devem ser enunciadas e outras silenciadas para que os leitores do presente trabalho produzam e colham os frutos da produção da sua leitura.

Em 2009, o Instituto Pró-Livro reeditou sua pesquisa realizada em 2007, que teve como meta desenhar o perfil de leitores no Brasil. Intitulou-a "Retratos da Leitura no Brasil", dada a amplitude e abrangência alcançadas. Entre os resultados obtidos junto a 172.731.959 brasileiros, amostra representativa da população, esse trabalho informa que três em cada quatro brasileiros atribuem à leitura um significado positivo. Quando solicitados a apresentar uma resposta espontânea e única quanto ao significado que tem para eles a leitura, destacamse os seguintes resultados: conhecimento (26\%); importante (8\%) e crescimento pessoal (8\%). Porém, quando instigados a responder, tendo de escolher uma das dez opções apresentados, os resultados apontaram o conhecimento como o valor mais associado (69\%). Esse levantamento permitiu verificar que a importância da leitura para o conhecimento é reconhecida entre a população mais velha e escolarizada. Para estes, a leitura é reconhecida como uma fonte de conhecimento para a vida (42\%), para a atualização profissional (17\%) e para a escola/faculdade (10\%). 
Os resultados apresentados na Tabela 1 dão conta de que a aprendizagem e o lazer foram as funções da leitura mais valorizadas pelos participantes deste trabalho. De certo modo, as informações colhidas pela escala utilizada evidenciam parte dos resultados referidos no relatório produzido pelo Instituto Pró-Livro, e para ele convergem, uma vez que os participantes, professores de Ensino Médio, reconhecem a importância instrumental da leitura para a aquisição de novos conhecimentos e para o lazer. Em Retratos da Leitura no Brasil, os resultados quanto ao que move a população brasileira a ler um livro, quando a amostra foi estimulada a assinalar três opções, foram os que seguem: prazer, gosto ou necessidade espontânea (63\%); atualização cultural ou conhecimentos gerais (53\%); exigência escolar ou acadêmica (43\%); motivos religiosos (26\%); atualização profissional (23\%); exigência do trabalho $(11 \%)$.

\section{CONSIDERAÇÕES FINAIS}

A importância atribuída à leitura deve sempre ser analisada, refletida e avaliada pelos socializadores, especialmente professores. Entre estes, nomeadamente, os que atuem junto a alunos em formação para serem certificados como professores das séries iniciais da escolarização, como é o caso dos participantes deste trabalho. Isso, porque os efeitos de uns refletem-se nos outros, direta e indiretamente. Na construção inicial e continuada de leitores, os comportamentos e dimensões afetivas desses profissionais, como as da valoração que atribuem à leitura, assumem um papel relevante: como modelos e ao possibilitarem condições efetivas para que seus alunos não só atribuam valor à leitura, quanto experimentem os benefícios e satisfações em realizá-la, como sugerido por Brophy (2009).

Sendo a escola um dos espaços sociais relevantes para a formação e a constituição de leitores, cabe a cada professor desempenhar seu ofício efetivamente, o que lhe demanda a (re)construção contínua de conhecimentos disciplinares e não-disciplinares (NÓVOA 1992; PERRENOUD 1999; TARDIF 2002), entre esses os que advêm da sua reflexão crítica acerca da origem e manutenção das próprias crenças. Isso, porque tais crenças marcam suas práticas educativas (SILVA, 1999; PAJARES, 1992). 
Não obstante se admitir que a leitura de textos específicos relacionados à busca de formação acadêmica e profissional realizada por professores possa, muitas vezes, ser caracterizada como leitura de trabalho (SARTI; BUENO, 2007), porque realizada para atender a necessidades e à resolução de problemas, que os participantes do presente trabalho poderiam estar enfrentando quando do levantamento realizado, há que se destacar que para muitos deles o prazer em realizá-las é evidente (vejam-se, na Tabela 1, os valores gerais para as funções aprendizagem, lazer, utilidade e estímulo). Por si exemplificam que a leitura não é movida apenas por aspectos cognitivos. Como as demais atividades, a leitura ocorre pelos efeitos do conjunto das dimensões afetivas que integram a motivação para realizá-la, entre estas as do valor a ela atribuído, como explicado por Brophy (1999), Linnenbrink e Pintrich (2004) e Hidi et al.(2004).

O envolvimento afetivo e a motivação para realizar leituras, por parte de professores, podem favorecer, por sua vez, atitudes positivas em relação à leitura em seus alunos, conforme demonstrado por esses autores e por Cramer e Castle (2001). Isso, porque as estratégias e as metas motivacionais dos professores surtem efeitos junto aos alunos: podem auxiliá-los a perceber as principais razões para se envolverem nas tarefas necessárias à aprendizagem com motivação para aprender, por exemplo, ao lerem os textos de estudo que lhes foram prescritos, bem como os ajudando a manter a confiança de que podem completar a atividade com sucesso e atingir os resultados pretendidos (BROPHY, 2009).

As limitações do presente estudo circunscrevem-se, em primeiro lugar, às relativas e decorrentes do instrumento utilizado. A natureza verbal deste e de apenas quatro opções colocadas para o respondente selecionar limitam em parte as conclusões possíveis. Seriam necessários mais dados, levantados a partir de entrevistas de profundidade, por exemplo, junto a alguns desses participantes, ou, ainda, obtidos pela observação das práticas que os professores adotam quando prescrevem leituras para seus alunos e as trabalham em sala de aula. O cruzamento dessas informações poderia delinear contornos mais precisos acerca dos efeitos das dimensões simbólicas e afetivas que circunscrevem a leitura desses professores e definir em que medida elas afetam sua prática educativa, particularmente a motivação de seus alunos para lerem. 


\section{REFERÊNCIAS}

AMORIN, G. (Coord.). Retratos da leitura no Brasil. São Paulo, SP: Instituto Pró-Livro, 2009. Disponível em: <http://www.prolivro.org.br>. Acesso em: 15 ago. 2009.

ANDERMAN, E. M. et al. Learning to value mathematics and reading: relations to mastery and performance-oriented instructional practices. Contemporary Educational Psychology, Maryland, v. 26, p. 76-95, 2001.

BERGER, P. L.; LUCKMANN, T. A construção social da realidade. Petrópolis: Vozes, 2001.

BROPHY, J . Conneting with the big picture. Educational Psychologist, New Jersey, v.44, n. 2, p.147-157, 2009.

Toward a model of the value aspects of motivation in education: developing appreciation for particular learning domains and activies. Educational Psychologist, New Jersey, v. 39, n. 2, p.75-85, 1999.

BOURDIEU P.; CHARTIER, R. A leitura: uma prática social - debate entre Pierre Bourdieu e Roger Chartier. In: CHARTIER, R. Práticas de leitura. São Paulo, SP: Estação Liberdade, 1996. p. 221-226.

BZUNECK, J. A. Como motivar os alunos: sugestões práticas In: Boruchovich, E. Bzuneck, J. A.; Guimarães, S. E. R. (Org.). Motivação para aprender: temas atuais e aplicações no contexto educativo. Petrópolis, RJ: Vozes, 2010 (no prelo).

O esforço nas aprendizagens escolares: mais do que um problema motivacional do aluno. Revista Educação e Ensino-USF, Itatiba, v.6, p.7-18, 2001.

CAVALlO, G.; CHARTIER, R. (Org.). História da leitura no mundo ocidental. São Paulo, SP: Ática, 1998.

CARVALHO, M. G. Representações Sociais da leitura de professores do ensino médio. 1999. 165f. Dissertação (Mestrado em Educação) - Departamento de Educação, Universidade Estadual de Londrina, Londrina, 2009.

CHARTIER, R. A aventura do livro: do leitor ao navegador. São Paulo: UNESP, 1998. $191,1991$.

O mundo das representações. Estudos Avançados, São Paulo, v.11, n. 5, p. 173-

(Org.). Práticas de leitura. São Paulo, SP: Estação Liberdade, 2001.

CRAMER, E. H.; CASTLE, M. Desenvolvendo leitores para toda a vida. In: . (Org.).

Incentivando o amor pela leitura. Porto Alegre: Artes Médicas, 2001. p. 13-20. 
FREIRE, P. A importância do ato de ler: três artigos que se completam. 12. ed. São Paulo, SP: Cortez, 1986.

GARCIA, T. I. O giro lingüístico. In: Iñiguez, L. (Org.). Manual de análise de discurso em ciências sociais. Petrópolis: Vozes, 2004. p. 19-49.

GIMENO SACRISTÁN, J. A educação que ainda é possível: ensaios sobre a cultura para a educação. Porto: PortoEd, 2008.

GOULEMOT, J. M. Da leitura como produção de sentidos. In: CHARTER, R. Práticas da leitura. São Paulo, SP: Estação Liberdade, 1996. p. 1107-116.

GREANEY, V.; NEWMAN, S. B. The function of reading: a cross cultural perspective. Reading Research Quarterly, Newark, v.25, n.3, p. 172-195. 1990.

GUEDES, P. C.; SOUZA, J. M. de. Leitura e escrita são tarefas da escola e não só do professor de português. In: Neves, I. C. B.(Org). Ler e escrever: compromisso de todas as áreas. 8. ed. Porto Alegre: UFRGS, 2007. p.17-22.

HIDI, S.; RENNINGER, K. A; KRAPP, A. Interest, a motivational variable that combines affective and cognitive functioning. In: DAI, D. Y.; STERNBERG, R. J. (Ed.). Motivation, emotion, and cognitition. Mahwah, NJ: Erlbaum, 2004. p. 89-115.

HUSMAN, J.; DERRYBERRY, W. P.; CROWSON, H.M.; E LOMAX, R. Instrumentality, task value, and intrinsic motivation: making sense of their independent interdependence. Contemporary Educational Psychology, Maryland, v. 29, p. 63-76, 2004.

JEAN, G. A escrita - memória dos homens. Rio de Janeiro, RJ: Objetiva, 2002.

LINNENBRINK, E. A.; PINTRICH, P. R. Role of affect in cognitive processing in academic contexts. In: Dai, D.Y. ; Sternberg, R. J. (Ed.). Motivation, emotion and cognition. New Jersey: Lawrence Erbaum Associates, 2004. p. 57-87.

LARROSA, J. Literatura, experiência e formação. In: COSTA, M. V. (Org.) Caminhos investigativos: novos olhares na pesquisa em educação. 2. ed. Rio de Janeiro, 2002. p.133-60.

LOPES, T. M. J; RIBEIRO, M. S. P. Funções de Leitura entre graduandos em biblioteconomia. Trans-in-formação, Campinas, v.4, n. 1; 2; 3, 1992, p. 45-54.

MARCUSCHI, L. A. Leitura e compreensão de texto falado e escrito como ato individual de uma prática social. In: ZIBERMAN, R; SILVA. E. T. Leitura: perspectivas interdisciplinares. São Paulo, SP: Ática, 1998. p. 38-57.

MARTINS, L. N. R.; COSENZA, M. Contextos de leitura em professores universitários. In: WITTER, G. P. (Org.). Leitura e Psicologia. Campinas: Alínea, 2004. p. 77-91. 
MOREIRA, L. de S. G. Leitura - atitudes e práticas de futuras professoras. $2007.175 \mathrm{fl}$. Dissertação (Mestrado em Educação) - Departamento de Educação, Universidade Estadual de Londrina, Londrina, 2007.

NÓVOA, A. (Org.). Os professores e sua formação. Lisboa: Publicações Dom Quixote, 1992.

OLIVEIRA, M. H. M. A. A leitura do universitário: estudo comparativo entre os Cursos de Engenharia e Fonoaudiologia da PUCCAMP. 168 fl. Dissertação (Mestrado em Psicologia) - Pontíficia Universidade Católica de Campinas, Campinas, 1993.

Funções da leitura para estudantes de graduação. Psicologia Escolar e Educacional, Campinas, v.1, n.1, p.61-68, 1996.

PERRENOUD, P. Práticas pedagógicas, profissão docente e formação: perspectivas sociológicas. Lisboa: Dom Quixote, 1993.

PINTRICH, P. R., \& SCHUNK, D. H. Motivation in education: theory, research, and applications. Englewood Cliffs, NJ: Merrill-Prentice Hall, 1996.

PULLIN, E. M. M. P.; ALMEIDA, C. J. C; LAWARD, D.; FERNANDES, F. P. R. Práticas de leitura e formação de professores. In: SEMINÁRIO INTERNACIONAL DE EDUCAÇÃO 1, 2001, Cianorte. Anais ... Cianorte: Universidade Estadual de Maringá, 2001.

SARTI, F. M.; BUENO, B. Leituras profissionais docentes e apropriação de saberes acadêmico-profissionais. Cadernos de Pesquisa, São Paulo, v. 37, n. 131, p.455-479, 2007.

SIEGEL, S. Estatística não paramétrica para as ciências do comportamento. São Paulo, SP: McGraw-Hill do Brasil, 1977.

SILVA, E. T. Concepções de leitura e suas conseqüências no ensino. Perspectiva, Florianópolis, v. 17, n. 31, p. 11-20, 1999.

Leitura: perspectivas interdisciplinares. São Paulo, SP: Ática, 1998.

SQUIRES, D.; BLISS, T. Teacher visions: navigating beliefs about literacy learning. The Reading teacher, Newark, v. 57, n. 8, p. 756-763, 2004.

SCRIBNER, S; COLE, M. The psychology of literacy. Cambridge: Harvard University, 1999.

TARDIF, M. Saberes docentes e formação profissional. Petrópolis: Vozes, 2002.

LINEK, W.M.; SAMPSON, M. B. ; RAINE, I. L.; KLAKAMP, K. ; SMITH, B.

Development of literacy beliefs and practices: preservice teachers with reading specializations in a field-based program. Reading Horizons, Kalamazoo, v. 46, n. 3, p.183-213, 2006. 
PAJARES, M. F. Teachers' beliefs and educational research: cleaning up a messy construct. Review of Educational Research, Pittsburgh, v. 62, n. 3, p.301-332, 1992.

RAYNER, K. et al. How psychological science informs the teaching of reading.

Psychological Science in the Public Interest, Washington, v. 2, n. 2, p.31-74, 2001.

WIGFIELD, A.; ECCLES, J. S. Expectancy-value theory of achievement motivation.

Contemporary Educational Psychology, Maryland, v. 25, p. 68-81, 2000.

ELSA MARIA MENDES PESSOA PULLIN

Pedagoga pela Faculdade Estadual de Filosofia, Ciências e Letras de Londrina, Mestre e Doutora pelo Instituto de Psicologia da USP. Professora Associada do Departamento de Educação da Universidade

Estadual de Londrina.

E-mail: pullin@uel.br

\section{MARIA DE CARVALHO GOMES}

Psicóloga pelo Centro Universitário Filadélfia de Londrina; Especialista em Psicopedagogia e em Análise do Comportamento pela Universidade Estadual de Londrina Mestre em Educação por essa IES. Bolsista da CAPES.

E-mail: maria.cgomes@bol.com.br

Recebido em: 20/08/2009

Publicado em: 30/10/2009 